\title{
O VIOLÃO NA EDUCAÇÃO MUSICAL: ABORDAGENS E METODOLOGIAS
}

Maxwell Ferreira Silva ${ }^{1}$

\section{RESUMO}

Gabriela Lelis Euzito Silva ${ }^{2}$

O presente artigo tem como objetivo apresentar algumas das reflexões, alternativas e abordagens no ensino do violão como instrumento na educação musical, para que docentes possam seguir e desenvolver com os estudantes, além das prováveis dúvidas que podem surgir a professores no processo de ensino, visando direcionar os educadores à reflexões e pensamentos críticos no desenvolver de suas próprias abordagens com base nos tópicos apresentados nesta pesquisa de caráter bibliográfico. Entre as questões pesquisadas estão: o ensino coletivo ou individual, provocando o interesse dos alunos, alternativas no ensino com violão, erudito ou popular, abordagens e aprendizagem.

Palavras-chave: Ensino. Violão. Abordagens. Metodologias.

\begin{abstract}
This article aims to present some of the reflections, alternatives and approaches in guitar teaching as an instrument in music education, so that teachers can follow and develop with students, besides the probable doubts that may arise for teachers in the teaching process, aiming at to direct educators to reflections and critical thoughts in developing their own approaches based on the topics presented in this bibliographic research. Among the questions researched are: collective or individual teaching, provoking student interest, alternatives in teaching with guitar, erudite or popular, approaches and learning.
\end{abstract}

Keywords: Teaching. Guitar. Approaches. Methodologies.

\section{RESUMEN}

Este artículo tiene como objetivo presentar algunas de las reflexiones, alternativas y enfoques en la enseñanza de la guitarra como instrumento en la educación musical, para que los maestros puedan seguir y desarrollarse con los estudiantes, además de las posibles dudas que puedan surgir a los maestros en el proceso de enseñanza, con el objetivo de dirigir a los educadores a reflexiones y pensamientos críticos en el desarrollo de sus propios enfoques basados en los temas presentados en esta investigación bibliográfica. Entre las preguntas investigadas se encuentran: la enseñanza colectiva o individual, provocando el interés de los alumnos, alternativas en la enseñanza con guitarra, clásica o popular, enfoques y aprendizajes.

Palabras clave: Docencia. Guitarra. Enfoques. Metodologías.

\footnotetext{
${ }^{1}$ Mestrando em Ciências da Educação pela FICS - Facultad Interamericana de Ciencias Sociales, Especialista em Música na Educação pela FACI - Faculdade de Tecnologia de Cachoeiro de Itapemirim, Especialista em Música e Artes pela FAVENI Faculdade Venda Nova do Imigrante, Graduado em Licenciatura em Música pelo CBM-CEU - Conservatório Brasileiro de Música-Centro Universitário/RJ, max_fsilva@ hotmail.com.

${ }^{2}$ Mestrando em Ciências da Educação pela FICS - Facultad Interamericana de Ciencias Sociales, Especialista em Música e Artes pela Faculdade Futura, ICETEC, Brasil, Especialista em Musicoterapia pelo ISEAC - Instituto Superior de Educação de Afonso Cláudio, Graduada em Licenciatura em Música pelo CBM-CEU - Conservatório Brasileiro de Música-Centro Universitário/RJ, gabriela_musicista@hotmail.com.
} 


\section{INTRODUÇÃO}

Mediante estudos como professor de guitarra, violão, educação musical, surgem-se distintas dúvidas sobre qual a metodologia correta para determinado educando. Com essa demasiada dúvida, aproveita-se essa pesquisa em forma de artigo, para observar e analisar abordagens e metodologias utilizadas por educadores, com o objetivo de traçar alternativas no ensino-aprendizagem do instrumento musical violão na Educação Musical. Com um breve histórico referente ao ensino coletivo, acreditando-se que esta seja uma prática vinda da Europa e em seguida para os Estados Unidos. É citado por Enaldo Oliveira alguns pontos que foram favoráveis pelo declínio do ensino coletivo nos Estados Unidos. Conseguinte, o artigo direciona-se sobre o ensino popular e erudito, citando técnicas, posturas e estudos. Sendo de suma importância para o ensino do violão, é vinculada algumas citações dos educadores: Shinichi Suzuki (FONTERRADA 2008), Sá Pereira, Villa-Lobos e Koellreutter (PAZ, 2013).

\footnotetext{
Na última década, o conceito de aprendizado musical vem sendo transformado e desenvolvido gradativamente na concepção de teóricos e educadores. Os professores de violão têm revisto concepções e fundamentos, movidos pela necessidade de acompanhar as rápidas transformações exigidas pelo exercício profissional. A mídia e o acesso fácil à música comercial têm depositado uma carga de informações diversificadas e profusas, que parecem influenciar de maneira muito forte aquilo que crianças e jovens pensam que seja "tocar um instrumento" e "aprender música" (TOURINHO, 2003, p.77).
}

\subsection{OBJETIVO}

Contribuir para o desenvolver de pesquisas em diversos aspectos, buscando o crescimento por parte de educadores e educandos que utilizam o instrumento musical violão como um dos instrumentos em suas abordagens na iniciação do aprendizado musical.

\subsection{METODOLOGIA}

Trata-se de pesquisa em cunho bibliográfico, onde, buscou-se analisar citações, metodologias e abordagens em sites científicos como Scielo, Google Acadêmico e universidades, além de livros com publicações entre os anos de 1982 a 2013, utilizando os seguintes descritores: Rubem Alves, Marisa Trench de Oliveira Fonterrada, Paulo Freire, Sergio Guimarães, Emerlinda A. Paz, Philippe Perrenoud, Norton Dudeque. Por meio dos referenciais: Flavia Maria Cruvinel, Cristina Tourinho, Enaldo Oliveira, Maurício Galindo, Valmir Antônio de Oliveira, Elodie Bouny, Cícera F. Teixeira, Maurício Sá Barreto Teixeira. A pesquisa se direciona mediante as vantagens e desvantagens do ensino coletivo ou individualizado, citando benfeitorias por ambas propostas do ensino. Com essas mudanças 
ocorrentes, este artigo irá citar pensamentos, metodologias e abordagens diante de renomados educadores.

\section{COLETIVO OU INDIVIDUAL}

Por intermédio de pesquisas, é possível observar que o ensino coletivo de instrumentos musicais no Brasil vem sendo realizado a décadas, acreditando, que seja uma prática vinda da Europa em seguida para os Estados Unidos. No final do século XIX marcou como ponto baixo os ensinos coletivos nos Estados Unidos, isso em razão ao aparecimento de cursos em nível superior em música, com a finalidade da especialização do interprete por intermédio do ensino individual. Alguns pontos foram favoráveis por esse declínio do ensino coletivo nos Estados Unidos, como cita Enaldo Oliveira In Cruvinel (2005):

\footnotetext{
...o ensino coletivo era praticado com um grande número de alunos por classe, e onde todos tocavam ao mesmo tempo; a fase dos conservatórios, com classes de quatro alunos que se revezavam na execução prática; e finalmente, a fase das escolas públicas, com um grande número de alunos, por classe, se exercitando em conjuntos (OLIVEIRA, 1998, p. 9, apud CRUVINEL, 2005, p. 68).
}

O grande começo de um ensino coletivo de música no Brasil se deu por meio de Heitor Villa Lobos na era Vargas, mediante o Canto Orfeônico, a convite do interventor federal do Rio de Janeiro, João Alberto. Em seguida, recebeu um convite de Anísio Teixeira, secretário de educação do então Distrito Federal, para tomar a direção da Superintendência de Educação Musical Artística (CRUVINEL, 2005).

\footnotetext{
Villa Lobos assumiu no ano de 1932 a direção da Superintendência de Educação Musical Artística (SEMA), no cargo de supervisor e diretor da Educação Musical do Brasil, "onde organizou o ensino de canto orfeônico, pondo em prática seu princípio de que a salvação da música brasileira dependia da formação básica da juventude e de que o canto coletivo era o melhor meio de educação social" (Publifolha, 1998, p.819, apud CRUVINEL, 2005, p. 70).
}

Ensino coletivo ou individual? Esta de certa forma, pode ser uma das dúvidas do professor de música. Olhando pelo lado financeiro, sendo os alunos pagantes, o professor ou a instituição poderão aumentar seus lucros em aulas coletivas, mas, e os alunos será que irão lucrar? O conhecimento chegará com mais qualidade ao aluno individual ou ao que estuda em grupo?

O trabalho em grupo, é citado por Teixeira (1999) como desenvolvedor cognitivo por meio de trocas: 
É na discussão com os colegas que a criança exercita sua opinião, sua fala, seu silêncio, defendendo seu ponto de vista. O trabalho em grupo, portanto, estimula o desenvolvimento do respeito pelas ideias de todos, a valorização e discussão do raciocínio; dar soluções e apresentar questionamentos, não favorecendo apenas a troca de experiência, de informações, mas criando situações que favorecem o desenvolvimento da sociabilidade, da cooperação e do respeito mútuo entre os alunos, possibilitando aprendizagem significativa. A relação com o outro, portanto, permite um avanço maior na organização do pensamento do que se cada indivíduo estivesse só (TEIXEIRA 1999, p. 26).

Entende-se que as aulas coletivas podem remeter os alunos a vários aspectos benéficos, como: o respeito a opiniões, considerações a colocação do próximo, troca de informações, argumentações, ouvir e conhecer abordagens diferenciadas, entre outros. Prontamente nas aulas individuais, podemos considerar uma especialização, em que o educando poderá ter a atenção exclusiva do professor, tendo a oportunidade de estudar as técnicas de uma forma mais detalhada, esse formato de aula pode ser escolhido por alunos tímidos, ou por aqueles que já possuem conhecimentos em seu instrumento, buscando algo mais específico. O perfil do professor que educa no ensino coletivo, de uma determinada maneira tem que ser diferente daquele que atua no ensino individual. Segundo Alberto Jaffé (Cruvinel, 2005, p.77) "acredito que o modelo de aula coletiva exige do professor qualidades especiais, como, carisma, e habilidade verbal". Em aulas coletivas é necessário que o professor atue claramente como um regente, dando as direções, sendo simpático, fazendo necessário uma postura de destaque em meio aos estudantes.

Outro ponto a ser lembrado, é que o conhecimento nunca chega da mesma forma para os educandos, por isso, é necessário que o professor busque caminhos diferenciados para levar os estudantes mediante o universo do saber. As dúvidas e discursões gerados em salas de aulas, sempre enriquecedora, promovem os alunos a entenderem e conhecerem caminhos diferenciados para um determinado conhecimento, essa questão também faz das aulas em grupo um momento grandioso na formação dos educandos. Por mais que os discentes sejam jovens, nunca chegam como uma folha em branco, carregam uma bagagem de cultura inserida em si. Segundo Perrenoud (2000) a escola não inicia o aprendizado a partir do zero:

A escola não constrói a partir do zero, nem o aprendiz não é uma tábula rasa, uma mente vazia; ele sabe, ao contrário, "muitas coisas", questionou-se e assimilou ou elaborou respostas que o satisfazem provisoriamente. Por causa disso, muitas vezes, o ensino choca-se de frente com as concepções dos aprendizes (PERRENOUD, 2000, p.26).

Não se pode deixar de citar os ótimos benefícios que as aulas individuais acarretam, como: os estudos particulares de técnicas, repertórios específicos, aperfeiçoamento de conhecimentos já adquiridos, estudos mais avançados, entre outros. Segundo Maurício Sá Barreto Teixeira, "A visão do músico instrumentista que deve ser um virtuose prevalece nos 
Conservatórios e Escolas de Música atualmente, com que as aulas devem ser individuais para elevar ao máximo a técnica de cada músico” (TEIXEIRA, 2008, p. 9). O ensino de música em grupo pode ser uma importante ferramenta nas escolas regulares, e é claro que professores formados, podem ter uma importante atuação, dando o direcionamento aos educandos.

Alguns pontos também podem desfavorecer o ensino coletivo, João Maurício Galindo (2002) In Cruvinel (2005), cita sobre a homogeneização das turmas: "A desvantagem é o seguinte: às vezes você tem de manter a turma homogênea (...) Pra manter a turma homogênea, você acaba sacrificando alguns. Mas é uma opção de democratização do ensino" (GALINDO, 2002, apud CRUVINEL, 2005, p. 101).

Podemos citar nomes que utilizam o ensino coletivo como metodologia eficiente na iniciação, como: Cristina Tourinho, Abel Moraes, Alberto Jaffé, José Coelho de Almeida, Pedro Cameron, Maria de Lourdes Junqueira, Diana Santiago, Alda Oliveira, Joel Barbosa, Maria Isabel Montandon, João Maurício Galindo, entre outros (CRUVINEL, 2008 p. 6).

\section{PROVOCANDO O INTERESSE}

Para o educador, é sempre excelente quando os estudantes estudam em casa e estão atentos para receber demasiado conhecimento, mas na prática nem sempre é assim. A citação abaixo de Rubem Alves, reflete-se em como o professor precisa promover o interesse do discente, assim como a cozinheira provoca a fome. "O comer não começa com o queijo. O comer começa na fome de comer queijo [...], a tarefa do professor é a mesma da cozinheira: antes de dar a faca e queijo ao aluno, provocar a fome..." (ALVES, 2013, p. 68; p.75).

Sobre o ensinamento Paulo Freire (2013) diz:

\footnotetext{
...ensinar não é transferir conhecimento, mas criar as possibilidades para a sua produção ou a sua construção.

...quem forma se forma e re-forma ao formar e quem é formado forma-se e forma ao ser formado. É neste sentido que ensinar não é transferir conhecimento.

Quando entro em uma sala de aula devo estar sendo um ser aberto a indagações, à curiosidade, às perguntas dos alunos, a suas inibições; um ser crítico e inquiridor, inquieto em face da tarefa que tenho - a de ensinar e não a de transferir conhecimento (FREIRE, 2013 p. 24; p. 25; p.47).
}

O professor seja em qual disciplina for, deve envolver-se para saber se realmente os educandos estão compreendendo, assim como uma questão de Saint-Onge (1996): “Eu, ensino, mas eles aprendem?" (SAINT-ONGE, 1996, apud PERRENOUD, 2000, p. 22). Se necessário for, pode ser que o docente tenha que buscar alternativas para levar o conhecimento, tendo em mente que as dificuldades e facilidades são díspares para discentes do mesmo nível. O trabalho do professor é promover o interesse dia a dia dos estudantes, para que torne um momento mais 
agradável entre o educador e educando, gerando uma via de mão dupla por meio do conhecimento.

\title{
4. ALTERNATIVAS NO ENSINO COM VIOLÃO
}

Geralmente em projetos ou ambientes que possuam aulas de música, tendo o violão como um dos instrumentos a serem ensinados, existe uma grande procura, podendo até ser o de maior quantidade, isso ocorre visto que é um instrumento bastante expandido. Valmir Antônio de Oliveira (2013) diz:

O violão é um instrumento que se insere bem em diversas culturas, transita facilmente pela música tradicional, erudita e popular, assim como é bem aceito nas diferentes camadas da sociedade, podendo ser considerado, em nosso país, um instrumento bem difundido e democrático (OLIVEIRA, 2013, p. 7).

O Violão é um instrumento que de certa maneira, suas formas de aprendizado vêm se transformando ano após ano, com surgimentos de novos métodos e abordagens, sendo um instrumento de várias qualidades e de fácil manuseio, podendo ser utilizado em várias faces da educação, tanto no ensino formal (reconhecido, ou seja, oficializado, aquele que ocorre nos sistemas de ensino tradicional), não formal (como escolas de músicas, oficinas, cursos, fora dos padrões do ensino formal), ou informal (pode-se dizer que pela vivência, por meio de famílias, amigos, vizinhos, religiões, meios de comunicações em massas). No Brasil no que diz respeito ao aprendizado "não formal", o violão é fonte geradora de inúmeros manuais de ensino, segundo Valmir Antônio Oliveira (2013):

\begin{abstract}
A educação não-formal ou aprendizagem espontânea, é um dos modos pelos quais o violão se constituiu na cultura brasileira pois, por muito tempo, antes do advento dos modernos meios de comunicação, todas as tradições, riqueza e diversidade da nossa cultura popular estiveram muito atadas à condição de transmissão oral, de geração para geração, tornando-se um meio de conexão entre passado e presente. É, entretanto, importante ressaltar certos aspectos próprios do ensino não formal, e que é, muito comumente, o meio tradicional do ensino e da aprendizagem do violão, em nosso país; assim se constituiu a construção de saberes de grande parte de artistas atuantes no cenário profissional brasileiro (OLIVEIRA, 2013, p. 58).
\end{abstract}

Em um diálogo entre Paulo Freire (1982) e Sérgio Guimarães (1982), com o tema partir da infância, é citado de como ele recebeu o ensino informal por meio de seus pais:

Paulo - Eu me lembro exatamente... Agora, na volta ao Brasil, visitei a casa, o quintal. ...me lembro exatamente... das duas mangueiras... no meio das quais meu pai dependurava a rede... me lembro daquele pedaço de alguns metros que possibilitavam o ir e vir da rede, e que tinha uma área assim bem limpa no chão. Minha mãe costumava sentar ao lado, numa cadeira de vime. . . meu pai balançava-se.... Eu tenho no ouvido ainda o ranger, com atrito, da rede.... Não que eles tivessem feito daquele a escola minha. E isto é que eu acho formidável: a informação 
e a formação que me iam dando se davam num espaço informal, que não era o escolar, e me preparavam para este, posteriormente (FREIRE, 1982, p. 15).

\section{ERUDITO OU POPULAR}

Para o educador, pode ser que seja preciso buscar entender a diferenciação entre erudito e popular, com o desígnio de os apresentar ao estudante, para que o mesmo se encontre musicalmente em ambas direções. Na dissertação de mestrado de Elodie Bouny a música erudita é citada como base segundo Billard e Philippot [s.d], "princípios tão robustos que a sua evolução se deu por inúmeros aperfeiçoamentos, sem nunca, até hoje, desacreditar no que já foi estabelecido nas aquisições anteriores” (BOUNY, 2012, p. 17).

A música erudita foi executada como base de escrita desde o século IX, tempo em que a partitura era o único meio de arquivar ou comunicar as ideias desde as mais simples as mais sofisticadas. Segundo o minidicionário da língua portuguesa Soares Amora, a palavra "erudito" quer dizer, "Que tem erudição; aquele que sabe muito" (AMORA, 2009, p. 271).

Normalmente nas músicas eruditas são utilizados violões com cordas de nylon. Para uma característica mais erudita, sabe-se que existem violões mais apropriados tanto tecnicamente, quanto sonoramente. Utilizam-se as técnicas dos arpejos, plaqué, rasgueos, geralmente nas obras eruditas são encontradas, melodia, harmonia e o baixo no mesmo sistema. Pode-se utilizar também o recurso das unhas grandes na mão direita, sendo o objetivo a obtenção de uma sonoridade mais clara, possibilitando um maior domínio, entre outras possibilidades. Oliveira (2013) diz:

\footnotetext{
Os efeitos tradicionais são os que compõem de maneira geral os recursos expressivos utilizados por todos os instrumentos. Caracteristicamente os efeitos são realizados de acordo com técnicas próprias de execução de cada instrumento, já consagradas através da trajetória de cada um e do próprio desenvolvimento da música (OLIVEIRA, 2013, p. 81).
}

Sobre as formas de execução, Oliveira (2013) In Sadie (1994) diz:

\footnotetext{
-Arpejos (dedilhado): origina da palavra harpa, e se caracteriza pela sucessão de notas de um acorde que soam em sequência. A forma de execução é uma imitação da maneira de como se toca harpa.

-Plaqué: Instrução para que se executem as notas de um acorde simultaneamente, em vez de sucessivamente.

-Rasgueos: é uma varredura das cordas, executadas no sentido ascendente e descendente, com o polegar e, respectivamente, o dorso das unhas ou a polpa dos dedos. Podem também ser executado com uma palheta. E característico da música flamenca, mas também muito utilizado em outras culturas (SADIE, 1994 apud OLIVEIRA 2013, p. 81-82).
} 
Também como característica do erudito, inclui a postura para segurar o violão, que as vezes utiliza um suporte de pé (denominado informalmente "banquinho") erguendo a perna esquerda posicionando o violão entre as duas pernas. Norton Dudeque (1994) diz:

\begin{abstract}
(...) as mudanças nas dimensões do violão, fazendo com que ele se tornasse um instrumento maior, fazem com que posteriormente o violonista Francisco Tárrega sugerisse um novo posicionamento para segurar e tocar o violão. Posição até hoje adotada, em que o violão é apoiado sobre a perna esquerda (DUDEQUE, 1994, p. 78).
\end{abstract}

Oliveira (2013) fala sobre o "banquinho": “...entre as duas pernas, visando basear-se no equilíbrio do instrumento com o nosso corpo, para que se obtenha um bom desempenho na sua execução, tendo o corpo como ponto fixo ou base" (OLIVEIRA, 2013, p. 20). Quanto ao violão popular, de certa forma, o estudo pode-se voltar mais à disciplina de harmonia, sendo mais um acompanhante de melodias. A priorização dos estudos técnicos e teóricos podem variar de acordo com seu estilo. Os instrumentos podem modificar de acordo com a preferência ou timbres para um determinado gênero musical, tendo violões com cordas de nylon ou aço, corpo e braço, largo ou não. Em relação a postura, pode-se utilizar sentado com pernas cruzadas ou não, e/ou em pé.

Yamandú Costa (2011), violonista de formação popular diz sobre postura:

\footnotetext{
Ela [a postura] é natural. Eu me mexo muito, não deixo cansar numa mesma posição. Sempre que vai começar a cansar o braço, já mudo, fico mudando de posição o tempo inteiro. Eu toquei muito de palheta e tenho muita referência de guitarra elétrica. Tive uma técnica muito boa de palheta entre 10 e 17 anos; então, isso também muda muito a posição da minha mão esquerda. Também, toquei muito de pé e criei uma mobilidade, naturalmente, levo o violão para onde quero (COSTA, 2011, apud BOUNY, 2012, p. 84)
}

Observando as posições, tanto erudita quanto popular, pode-se notar quase que claramente que a posição erudita é mais regrada, mantendo um padrão entre os músicos, por outro lado a postura do músico de formação popular parece ser mais espontânea, sem tal protocolo. Pode ser interessante o professor apresentar as possibilidades, mas não as impor. Bouny (2011) “...a posição do violonista de formação erudita é mais fixa, mais assessorada e mais uniformizada, mantendo certo padrão entre eles. $\mathrm{O}$ violonista de formação popular parece ter uma relação mais espontânea, sem formalidade e sem ritual com o instrumento" (BOUNY, 2011, p. 88).

\title{
6. ABORDAGENS E APRENDIZAGEM
}


Ao iniciar um processo de educação musical, tanto individualmente quanto em grupo, novamente surge as perguntas, qual o método? Qual abordagem? Assim, esse tópico traz determinados pensamentos e abordagens utilizados por alguns educadores.

\begin{abstract}
$\mathrm{Na}$ aprendizagem humana, o indivíduo primeiro aprende a falar para depois saber ler. O músico pode aprender, primeiro, a produzir sons e, posteriormente, entender o sinal gráfico que os representa. Isso facilita o processo de aprendizagem da leitura, já que os símbolos partem de uma prática musical. No processo inverso, símbolo, para o aluno, não possui significado concreto, nem utilização imediata (OLIVEIRA, 1998, p. 62, apud CRUVINEL, 2005, p.76).
\end{abstract}

Segundo a citação acima de Enaldo Oliveira (1998), por que não fazer que o aluno produza som antes de entender a escrita musical? De uma certa maneira, a procura em aprender a tocar, se dar na ansiedade de fazer música, e não em entender as figuras musicais, mas é claro que não fazendo menos importante. Pode ser que alguns concordam, e outros não, mas o fato é que a pesquisa pode sempre ser bom caminho para chegarmos a uma conclusão, ou ao menos no início dela.

Segundo Fonterrada (2008) Suzuki aborda em seu método que o aprendizado da leitura musical vem após o aluno já tocar.

No método Suzuki, o desenvolvimento da leitura musical é posterior ao aprendizado do instrumento. $\mathrm{O}$ aluno deve memorizar o que toca, antes de ler obras da literatura violinística no instrumento; assim, não faz exercícios de leitura à primeira vista, pois lê apenas o que já sabe de cor (FONTERRADA, 2008, p. 173).

A exemplo, Suzuki coloca alguns pontos como caminhos para a educação musical: repetição constante, utilização de discos e gravações, contato passivo com a criança e aceitação de seus esforços e possíveis falhas, oferecimento de oportunidades para tocar em público, formação de repertórios, estímulo a memória, estímulo à execução de ouvido, e a essencial presença dos pais. Fonterrada (2008) expõe:

A presença dos pais é fundamental; são eles que desempenharão o papel mais importante, porque em casa, diariamente, tocarão e estimularão a criança a tocar, transformando o aprendizado em atividade lúdica. O ambiente tem que ser "fabricado" pelos pais, com a minuciosa orientação de Suzuki (FONTERRADA, 2008, p. 170).

Antônio de Sá Pereira, acredita antes mesmo de focalizar seu método de musicalização, destaca a importância de a musicalização preceder o ensino do instrumento, sendo um prérequisito para o mesmo, para ele, antes da criança sentar-se ao piano, será necessário educar o ouvido (PAZ, 2013). 
Em vez de se ensinar teoria musical, abstrata e árida, decorada sem interesse e depressa esquecida, muito mais proveitoso seria, e de real valor para o resto da vida, iniciar as crianças na apreciação da música, apreciação livre, espontânea, realizada debaixo de real interesse (PEREIRA, 1937, apud PAZ, 2013, p. 48).

Villa-Lobos confia que se é preciso educar o ouvido, tendo a educação musical com gerações mais novas.

É indispensável orientar adaptar, nesse sentido, a juventude dos nossos dias, e começarmos este trabalho muito cedo com gerações mais novas, sobretudo as crianças de cinco a quatorze anos. Seu fim não é o de criar artistas nem teóricos de música senão cultivar o gosto pela mesma e ensinar a ouvir (VILLA-LOBOS, 1972, apud, PAZ, 2013, p. 15).

Por mais que adotamos métodos ou abordagens, pode ser que não deveríamos seguir à "risca", visto que, para atingirmos um objetivo na educação musical, talvez a mesma forma de ensino não funcione com todos os educandos. Há uma citação de Koellreutter (1987) que presenciei durante a graduação.

\footnotetext{
Tenho três premissas ou preceitos que norteiam meu trabalho:

1) não há coisa errada na música, a não ser aquilo que não se pode executar; errado é sempre errado relativo a alguma coisa; o errado absoluto em música não existe.

2) não acredite em nada que o professor diz; não acredite em nada que os professores dizem; não acredite em nada que você lê; não acredite em nada que você pensa; em outras palavras, questione sempre.

3) pergunte sempre: por quê? Se o professor não pode explicar o porquê, precisa então pensar um pouco! (KOELLREUTTER, 1987, apud PAZ, 2013, p. 223).
}

Então pode ser que exista importância em constantemente realizar-se pesquisas, para que se encontre alternativas no processo de ensino/aprendizagem visando o desenvolvimento do discente na Educação Musical.

\section{CONSIDERAÇÕES FINAIS}

Este artigo não tem como objetivo resolver ou transformar o ensino musical tendo o violão como instrumento musicalizador, e sim, pretende levar professores a buscar por meio das pesquisas e propostas apresentadas, a desenvolverem características próprias, apoiando ou não em métodos e/ou abordagens.

Podemos observar que existem diversos pensamentos relacionados ao ensino musical, dentre vantagens e desvantagens no ensino individualizado e/ou coletivo, além das abordagens diante do erudito e popular. Esta pesquisa tem como direcionamento instigar o docente a se preparar para induzir os educandos a ambas as direções, não fazendo com que fiquem somente em uma direção durante toda construção musical e que os educadores busquem suas próprias alternativas no processo do ensino. 
É de suma importância o professor voltar-se aos educandos para saber se realmente estão compreendendo, provocando o interesse por intermédio das abordagens e lembrando que os formatos de ensino/aprendizagem são díspares.

O violão em suas formas de aprendizado, vêm se transformando ano após ano, com surgimentos de novos métodos e abordagens, sendo um instrumento de várias qualidades e de fácil manuseio, presente em várias formas do ensino: formal, não formal e informal, como citado neste estudo.

Conclui-se que o ensino do violão como instrumento na educação musical é uma importante ferramenta, e não compete dizer o que é certo ou errado no que se trada em ensinoaprendizagem deste instrumento. As propostas aqui citadas, levam-nos a refletir sobre qual seria a melhor alternativa para o ensino deste. Acredita-se que tanto o ensino coletivo quanto o individualizado são importantes no processo de construção musical de cada discente. Sobre o erudito e o popular, é dever do professor apresentar ambas direções, tanto com composições populares e eruditas, estudos de acordes, leituras e escritas tradicionais, entretanto, inseri-los gradativamente nas aulas, de acordo com a vivência dos estudantes.

As abordagens presentes nesta pesquisa, são um início de um caminho para apontar o abranger deste trabalho, pesquisando: abordagens, métodos, dificuldades, facilidades, ideias, entre outros desdobramentos para levar o saber do instrumento violão, perante a educação musical.

\section{REFERÊNCIAS}

ALVES, Rubem. Ao Professor, com o meu carinho / Rubem Alves. - $1^{\text {a }}$ Edição. Pegue \& Leve. Rio de Janeiro, 2013.

AMORA, Antônio Soares, 1917-1999. Minidicionário Soares Amora da língua portuguesa / Antônio Soares Amora. - 19a . ed. - São Paulo: Saraiva, 2009.

BOUNY, Elodie. Violonista de formação erudita e violonista de formação popular: investigando diferenças na educação musical. Dissertação de Mestrado, Universidade Federal do Rio de Janeiro, 2012.

CRUVINEL, Flavia Maria. Educação musical e transformação social - uma experiência como ensino coletivo de cordas / Flavia Maria Cruvinel. - Goiânia: Instituto Centro-Brasileiro de Cultura, 2005.

O Ensino Coletivo de Instrumentos Musicais na Educação Básica: compromisso com a escola a partir de propostas significativas de Ensino Musical. Artigo apresentado no VIII Encontro Regional Centro-Oeste da Associação Brasileira de Educação Musical, $1^{\circ}$ Simpósio sobre o Ensino e a Aprendizagem da Música Popular e III Encontro Nacional de Ensino Coletivo de Instrumento Musical realizados em Brasília, no período de 21 a 23 de agosto de 2008. Disponível em <http://www.ufrgs.br/musicalidade/midiateca/praticas-musicais-vocais-einstrumentais/praticas-instrumentais >. Acesso em 03 mar. 2018.

DUDEQUE, Norton. História do Violão. Curitiba: Ed. Da UFPR, 1994.

FONTERRADA, Marisa Trench de Oliveira, 1939 - De tramas e fios: um ensaio sobre música e educação. - $2^{\mathrm{a}}$ ed. - São Paulo: Editora UNESP; Rio de Janeiro: Funarte, 2008.

FREIRE, Paulo. Sobre educação: diálogos / Paulo Freire e Sérgio Guimarães. - Rio de Janeiro: Paz e Terra, 1982. 
Pedagogia da autonomia: saberes necessários à prática educativa / Paulo Freire $-47^{\mathrm{a}}$ ed - Rio de Janeiro: Paz e Terra, 2013.

OLIVEIRA, Valmir Antônio de. Violão e educação musical: Por uma metodologia de musicalização com o violão. Dissertação de Mestrado, Universidade Federal do Rio de Janeiro, 2013.

PAZ, Emerlinda A., 1949. Pedagogia musical brasileira no século XX. Metodologias e tendências. 2.ed. revista e aumentada - Brasília: Editora MusiMed, 2013.

PERRENOUD, Philippe. Dez novas competências para ensinar - Philippe Perrenoud; trad. Patrícia Chittoni Ramos. - Porto Alegre: Artmed, 2000.

TEIXEIRA, Cícera F. Compreensão, Criação e Resolução de Problemas de Estrutura Multiplicativa: uma sequência didática com problemas "abertos". Monografia. Recife: UFPE / Curso de especialização em ensino de pré a $4^{\text {a }}$ série. 1999.

TEIXEIRA, Maurício Sá Barreto. Ensino coletivo de violão: diferentes escritas no aprendizado de iniciantes. Monografia de fim de curso de licenciatura em música - Instituto Villa-Lobos, Centro de Letras e Artes, Universidade Federal do Estado do Rio de Janeiro, 2008.

TOURINHO, A. C. G. S.. Aprendizado musical do aluno de violão: articulações entre práticas e possibilidades. In: Liane Hentschke; Luciana del Ben. (Org.). Ensino de Música, propostas para pensar e agir na sala de aula. São Paulo: Moderna, 2003, v. 01, p. 77-85. 